\begin{tabular}{|c|l|}
\hline Title & Dielectric breakdown and healing of anodic oxide films on al uminium under single pulse anodizing \\
\hline Author(s) & Sah, Santosh Prasad; Tatsuno, Y asuhiro; A oki, Y oshitaka; Habazaki, Hiroki \\
\hline Citation & $\begin{array}{l}\text { Corrosion Science, 53(5), 1838-1844 } \\
\text { https://doi.org/10.1016/.corsci.2011.02.001 }\end{array}$ \\
\hline Issue Date & 2011-05 \\
\hline Doc URL & http://hdl.handle.net/2115/47414 \\
\hline Type & article(author version) \\
\hline File Information & CS53_1838_1844.pdf \\
\hline
\end{tabular}

Instructions for use 


\title{
Dielectric breakdown and healing of anodic oxide films on aluminium under single pulse anodizing
}

\author{
Santosh Prasad Sah, Yasuhiro Tatsuno, Yoshitaka Aoki, Hiroki Habazaki* \\ Division of Material Chemistry, Faculty of Engineering, Hokkaido University, Sapporo 060-8628, \\ Japan
}

Corresponding author: Phone \& Fax: +81-11-706-6575, e-mail: habazaki@eng.hokudai.ac.jp

\begin{abstract}
Single pulse anodizing of aluminium micro-electrode has been employed to study the behaviour of dielectric breakdown and subsequent oxide formation on aluminium in alkaline silicate and pentaborate electrolytes. Current transients during applying pulse voltage have been measured, and surface has been observed by scanning electron microscopy. Two types of current transients are observed, depending on the electrolyte and applied voltage. There is a good correlation between the current transient behaviour and the shape of discharge channels. In alkaline silicate electrolyte, circular open pores are healed by increasing the pulse width, but such healing is not obvious in pentaborate electrolyte.
\end{abstract}

Keywords: A: aluminium, B: SEM, C: anodic films, C: oxide coating, 
1. Introduction

Plasma electrolytic oxidation (PEO), often also referred to as micro-arc oxidation (MAO), spark anodizing and micro-plasma oxidation, has attracted recent attention as a surface engineering process of light metals ( $\mathrm{Al}, \mathrm{Mg}$ and $\mathrm{Ti}$ ) and their alloys to form ceramic coatings [1-4]. The coatings can range from tens to hundreds of micrometres in thickness, and their improved thermo-mechanical properties, corrosion resistance and wear resistance [1, 5-9] are partly associated with the formation of high-temperature oxide phases, such as $\alpha-\mathrm{Al}_{2} \mathrm{O}_{3}$, during PEO processing. The process involves a large number of short-lived microdischarges, caused by dielectric breakdown of oxide coatings at high voltages. Rapid heating and cooling of the coatings by microdischarges form such highly crystalline, hightemperature phases. The microdischarges clearly play an important role in growth of PEO coatings [10]. They create characteristic discharge channels on the coating surface, with the channels becoming usually larger with the time of PEO treatment. Thus, large discharge pores of $>10 \mu \mathrm{m}$ in diameter, connecting from the oxide surface to the inner coating close to the metal/film interface, are often found in the PEO coatings.

Optical characterization of individual discharges has been carried out recently using video recording. Yerokhin et al. estimated from video imaging of $50 \mathrm{~Hz}$ AC PEO of aluminium that the microdischarge current density is as high as $18-50 \mathrm{kA} \mathrm{m}^{-2}$ and the durations of individual microdischarges are 0.25-3.0 ms [11]. Mécuson et al. recorded the discharge behaviour using fast CCD camera imaging with a time resolution of 2ms [12]. Voltage-dependent lifetime of microdischarges from $\sim 47 \mathrm{~ms}$ at $300 \mathrm{~V}$ to $\sim 335 \mathrm{~ms}$ at $470 \mathrm{~V}$ has also been reported during galvanostatic DC PEO of titanium [13]. However, Arrabal et al. revealed recently much shorter lifetimes in the range of 0.05-4 ms during AC PEO of magnesium alloys [14].

Relatively large discharge open channels, connecting to an inner region close to the metal/film interface, are undesirable in terms of corrosion protection and wear resistance. It has been recently reported that relatively thick intermediate layer with low porosity is formed between an inner barrier layer and an outer loose layer containing large cavities and 
pores under selected PEO conditions [8, 9, 12, 15-18]. The formation of the intermediate layer is correlated with so called "soft" sparking, which is characterized by a change in the optical emission spectra, reduction in the size of microdischarges and reduction in acoustic noise $[16,19]$. The importance of cathodic to anodic current ratio is reported to facilitate the formation of less porous intermediate layer [16]. In addition, to our knowledge, such intermediate layer in PEO coatings on aluminium is only formed in alkaline silicate electrolytes. It is also well known that the morphologies, phases and compositions of the PEO coatings are largely dependent upon electrolytes used [20].

In the present study, the influence of electrolyte on the dielectric breakdown and subsequent healing of anodic oxide films on aluminium during single pulse anodizing has been examined. The behaviour in alkaline silicate electrolyte has been compared with that in ammonium pentaborate electrolyte through the measurements of current transients during single pulse anodizing and observations of resultant surfaces. Microdischarges caused by dielectric breakdown are local events. Thus, a microelectrode of aluminium has been used in this study. This reduces the number of discharge events on entire surface, assisting more readily analysis of the breakdown behaviour.

\section{Experimental}

Highly pure aluminium wire (99.99\%, Nilaco Corporation, Tokyo) of $0.2 \mathrm{~mm}$ diameter was first anodized up to $450 \mathrm{~V}$ in $0.01 \mathrm{~mol} \mathrm{dm}^{-3}$ ammonium pentaborate electrolyte to cover the entire metal surface by a thick anodic oxide film. Then, the wire was embedded in resin. The embedded aluminium wire was sectioned by ultramicrotomy technique (RMC, MT-7) using a glass knife to expose clean and relatively flat surface.

Two electrolytes, shown in Table 1, were used in this study. A two-electrode cell was used for anodizing, and type-304 stainless steel container of electrolyte was used as a counter electrode. Initially, anodizing was carried out by voltage sweep up to $350 \mathrm{~V}$ at a rate of $3.5 \mathrm{~V} \mathrm{~s}^{-1}$ followed by holding the voltage for $50 \mathrm{~s}$. Then, a single pulse voltage in a range of 390 to $420 \mathrm{~V}$ was applied for a pulse width of $2 \mathrm{~ms}$ to $30 \mathrm{~ms}$ to cause dielectric 
breakdown. The voltage waveforms were fed from a Hokuto-Denko, HB-105 function generator to a Chroma 61501 Programmable AC Source. Current transients were recorded with a sampling time of $0.1 \mathrm{~ms}$ using an Agilent 3441A digital multimeter controlled by NI Labview software.

Surfaces of the specimens were observed by a JEOL JSM-6510 scanning electron microscope with EDS facilities. For selected specimens, anodic oxide films were stripped by chemical dissolution in a mixed solution of $20 \mathrm{~g} \mathrm{~L}^{-1} \mathrm{CrO}_{3}$ and $45 \mathrm{~g} \mathrm{~L}^{-1} \mathrm{H}_{3} \mathrm{PO}_{4}$ at $363 \mathrm{~K}$ for 1.8 ks to observe the morphologies of metal surfaces beneath the anodic oxide films.

\section{Results and discussion}

Fig. 1 shows the current transients during voltage sweep of aluminium microelectrode in alkaline silicate and pentaborate electrolytes. A current of $\sim 8 \mathrm{~mA} \mathrm{~cm}^{-2}$ flows both in the electrolytes below $\sim 350 \mathrm{~V}$ mainly to grow a barrier-type anodic oxide film. Then, an abrupt current increase occurs between 356-363 V, due to dielectric breakdown of anodic oxide films. After showing a current peak, the current decreases exponentially both in the electrolytes. An interesting fact is that the current density after dielectric breakdown becomes lower than that before breakdown in pentaborate electrolyte, suggesting that more resistive oxide is formed by dielectric breakdown in this electrolyte. The lower current density also suggests that the dielectric breakdown stops completely within $0.3 \mathrm{~s}$. Additional breakdown did not occur up to $366 \mathrm{~V}$, at which the voltage sweep was terminated. In contrast, the current density higher than that before breakdown flows after breakdown for more than $1 \mathrm{~s}$, probably suggesting continuous breakdown of anodic oxide in alkaline silicate electrolyte.

The surface morphologies after breakdown in alkaline silicate and pentaborate electrolytes (Fig. 2) are largely different, reflecting the electrolyte-dependent current transients. The aluminium surface anodized to $350 \mathrm{~V}$ in alkaline silicate electrolyte (Fig. 2a), at which no dielectric breakdown occurs, is relatively flat and only several knife marks 
are visible. Similar surface was observed after anodizing to $350 \mathrm{~V}$ in ammonium pentaborate electrolyte. After breakdown in alkaline silicate electrolyte (Figs. 2b and 2c), the entire surface is covered with an anodic oxide film modified by dielectric breakdown. The oxide surface is rough and the oxide film contains numbers of discharge pores with sizes of $\sim 1 \mu \mathrm{m}$ or less (Fig. 2c). Fine particles on the surface are probably precipitates derived from silicate in electrolyte.

Breakdown in pentaborate electrolyte produces a countable number of isolated discharge channels in the anodic oxide film (Fig. 2d). There are also surface regions where no discharge pores are present. The circular open discharge channels are generally 1-2 $\mu \mathrm{m}$ in size and they are surrounded by a band of evidently thicker film material, 500 nm wide, with multi-branched ridges being developed further in their surrounding area (Fig. 2e). These features of breakdown surface in pentaborate electrolyte are similar to those reported previously [21].

For further detailed understanding of the dielectric breakdown of anodic alumina, single pulse voltage was applied for $30 \mathrm{~ms}$. After anodizing at $350 \mathrm{~V}$ in alkaline silicate electrolyte, to which no dielectric breakdown occurs, a pulse voltage in a range of 390 to $420 \mathrm{~V}$ has been applied and current transients during applying pulse have been measured (Fig. 3a). A current peak, observed within 2 ms, increases with an increase in pulse voltage. Then, the current decreases sharply and a nearly constant current of several $\mathrm{A} \mathrm{cm}^{-2}$ flows between 10 and $30 \mathrm{~ms}$. Approximately similar current transient is found in pentaborate electrolyte at a pulse voltage of $420 \mathrm{~V}$, but the transient behaviour is different at voltages of 390 to $410 \mathrm{~V}$. The current decreases almost linearly with time in this voltage range (Fig. 3b).

There is a good correlation between current transients and morphology of discharge channels. In alkaline silicate electrolyte, in which current decreases sharply within $5 \mathrm{~ms}$, groove-like discharge channels are mainly found on the surface after pulse anodizing for 30 ms, regardless of applied pulse voltage (Figs. 4a and 4b). Similar groove-like discharge channels are developed at $420 \mathrm{~V}$ in pentaborate electrolyte, in which the current transient is 
similar to those in alkaline silicate electrolyte. When the current decreases linearly with time during applying pulse voltage, many circular open discharge channels are developed, as shown in Fig. 4d as an example.

The surface morphology is also slightly dependent upon pulse width. Fig. 5a shows the surface SEM image of the specimen after applying a pulse of $420 \mathrm{~V}$ for $2 \mathrm{~ms}$ in alkaline silicate electrolyte. When the shorter pulse of $2 \mathrm{~ms}$ is applied, circular discharge channels with open pores are found in addition to the groove-like channels, although the former morphology is not clearly seen after pulse anodizing for $30 \mathrm{~ms}$. This specimen was immersed in a mixed solution of chromic acid and phosphoric acid at an elevated temperature to strip the oxide film and to see the morphology of metal surface beneath the oxide film (Fig. 5b). Many recessions are found on the metal surface, being formed to heal an oxide film after destructive breakdown events. Dielectric breakdown should occur at all recession sites, since it is unlikely that recessions are formed during uniform growth of barrier-type anodic oxide films. However, open discharge pores, indicated by arrows, are found on parts of recessions, suggesting that some discharge pores are healed during pulse anodizing. Oxides formed at groove-like discharge channels are remained after chemical dissolution, as clearly seen from EDS imaging of aluminium (Fig. 5c) and oxygen (Fig. 5d). Temperature may increase markedly at the groove-like discharge channel regions, transforming amorphous alumina to crystalline one that usually has higher chemical stability.

Healing of open discharge pores appears to proceed further by increasing pulse width. Fig. 6 shows the surface SEM images of aluminium after pulse anodizing at $420 \mathrm{~V}$ for 2 ms (Figs.6a, b) and 30 ms (Figs. 6c, d). At both pulse widths, numbers of recessions of $\sim 1 \mu \mathrm{m}$ in size are found on the metal surface (Figs. 6b, d), while the number of obvious open discharge pores on the oxide surface is higher at shorter pulse width. Healing may proceeds by repeating discharge events. Partly-overlapped recessions found on metal surface (Fig. 5b) are one of the evidences for repeated discharge events even within a pulse width of 2 ms. 
Fig. 7 shows a region where groove-like discharge channel is developed. The metal surface beneath the groove-like discharge channel is disclosed by chance due to chemical dissolution of oxide in a mixed solution of chromic acid and phosphoric acid (Fig. 7b). Many overlapped recessions are found in the region, and this feature of the metal surface where the groove-like discharge channel is developed, implies that highly repeated discharges develop groove-like discharges. In the groove-like discharge regions, relatively thin oxide layers are formed after pulse anodizing for $10 \mathrm{~ms}$ as illustrated in Fig. 8a. The lower concentration of oxygen (Fig. 8c) and higher concentration of aluminium (Fig. 8b) is clearly seen inside of the groove, with a surrounding band showing increased oxygen concentration, due to the formation of a thicker oxide layer. Destructive breakdown events are concentrated in the groove-like surface regions, where sufficiently thick oxide is not reformed within $10 \mathrm{~ms}$. When the pulse width is increased to $30 \mathrm{~ms}$, the difference of the concentration of aluminium and oxygen between the groove-like surface regions and other regions where no discharge occurs, becomes less significant. Silicon is also detected more clearly after pulse anodizing for $30 \mathrm{~ms}$. The deposition of silicon species from electrolyte should be associated with thermo-chemical or plasma-chemical reactions at the discharged regions [20]. Although current is low between the pulse time of 10-30 ms, discharge should continue at least in the groove-like surface regions.

The surface morphology of aluminium in ammonium pentaborate electrolyte at 420 $\mathrm{V}$ resembles that in alkaline silicate electrolyte, but no healing of open discharge pores was found in the former electrolyte. Fig. 9 shows the oxide and metal surfaces of aluminium after pulse anodizing at $420 \mathrm{~V}$ for $30 \mathrm{~ms}$. Groove-like discharge channels and many recessions on metal surface beneath the groove-like oxide regions are similar to those formed in alkaline silicate electrolyte. In contrast, isolated open discharge pores are limited and on the metal recession sites, always open discharge pores are clearly seen. Thus, no obvious healing of discharge pores occurs in ammonium pentaborate electrolyte.

In PEO of aluminium in alkaline silicate electrolyte, less porous and relatively uniform oxide layer can be formed after transition to "soft" sparking [8, 9, 12, 15-18]. The 
present study reveals that healing open discharge pores occurs more readily during single pulse anodizing in alkaline silicate electrolyte, while such healing is not observed in ammonium pentaborate electrolyte. It is likely that soft sparking in PEO process in alkaline silicate electrolyte is associated with such healing behaviour in alkaline silicate electrolyte.

4. Conclusions

1) Current transients during applying a single pulse voltage on aluminium microelectrode are dependent upon electrolyte and applied voltage. In alkaline silicate electrolyte, current decreases rapidly within $5 \mathrm{~ms}$, followed by a nearly constant low current of $~ 10$ $\mathrm{A} \mathrm{cm}^{-2}$ or less up to $30 \mathrm{~ms}$, at all voltages examined. Similar current transient are found at $420 \mathrm{~V}$ in ammonium pentaborate electrolyte, while a linear current decrease is observed at lower temperatures.

2) Main shapes of characteristic discharge channels developed single pulse anodizing are correlated with the current transients. Isolated circular discharge channels are developed when the current decreases linearly during applying pulse. In contrast, groove-like discharge channels are formed mainly in addition to circular discharge channels when the current decreases rapidly with initial $5 \mathrm{~ms}$.

3) In alkaline silicate electrolyte, healing of circular discharge pores and thickening of an oxide layer within groove-like discharge channels proceed as the pulse width increases. Healing of discharge open pores dies not occur in ammonium pentaborate electrolyte.

\section{Acknowledgements}

The present work was supported in part by Grant-in-Aids for Scientific Research (A) No. 19206077 from the Japan Society for the Promotion of Science as well as by the Global COE Program (Project No. B01: Catalysis as the Basis for Innovation in Materials Science) from the Ministry of Education, Culture, Sports, Science and Technology, Japan. 
References

[1] A.L. Yerokhin, A.A. Voevodin, V.V. Lyubimov, J. Zabinski, M. Donley, Surf. Coat. Technol., 110 (1998) 140-146.

[2] A.L. Yerokhin, X. Nie, A. Leyland, A. Matthews, Surf. Coat. Technol., 130 (2000) 195-206.

[3] C. Blawert, W. Dietzel, E. Ghali, G.L. Song, Adv. Eng. Mater., 8 (2006) 511-533.

[4] G.E. Thompson, F. Monfort, E. Matykina, A. Berkani, P. Skeldon, Corros. Rev., 25 (2007) 631-650.

[5] A.L. Yerokhin, A. Shatrov, V. Samsonov, P. Shashkov, A. Pilkington, A. Leyland, A. Matthews, Surf. Coat. Technol., 199 (2005) 150-157.

[6] Q.Z. Cai, L.S. Wang, B.K. Wei, Q.X. Liu, Surf. Coat. Technol., 200 (2006) 37273733.

[7] J. Liang, B.G. Guo, J. Tian, H.W. Liu, J.F. Zhou, W.M. Liu, T. Xu, Surf. Coat. Technol., 199 (2005) 121-126.

[8] E. Matykina, R. Arrabal, A. Mohamed, P. Skeldon, G.E. Thompson, Corros. Sci., 51 (2009) 2897-2905.

[9] E. Matykina, R. Arrabal, P. Skeldon, G.E. Thompson, Surf. Interface Anal., 42 (2010) 221-226.

[10] F. Monfort, A. Berkani, E. Matykina, P. Skeldon, G.E. Thompson, H. Habazaki, K. Shimizu, J. Electrochem. Soc., 152 (2005) C382-C387.

[11] L. Yerokhin, L.O. Snizhko, N.L. Gurevina, A. Leyland, A. Pilkington, A. Matthews, J. Phys. D: Appl. Phys., 36 (2003) 2110-2120.

[12] F. Mecuson, T. Czerwiec, T. Belmonte, L. Dujardin, A. Viola, G. Henrion, Surf. Coat. Technol., 200 (2005) 804-808.

[13] E. Matykina, A. Berkani, P. Skeldon, G.E. Thompson, Electrochim. Acta, 53 (2007) 1987-1994.

[14] R. Arrabal, E. Matykina, T. Hashimoto, P. Skeldon, G.E. Thompson, Surf. Coat. Technol., 203 (2009) 2207-2220. 
[15] J.A. Curran, T.W. Clyne, Acta Mater., 54 (2006) 1985-1993.

[16] F. Jaspard-Mecuson, T. Czerwiec, G. Henrion, T. Belmonte, L. Dujardin, A. Viola, J. Beauvir, Surf. Coat. Technol., 201 (2007) 8677-8682.

[17] E. Matykina, R. Arrabal, D.J. Scurr, A. Baron, P. Skeldon, G.E. Thompson, Corros. Sci., 52 (2010) 1070-1076.

[18] E. Matykina, R. Arrabal, P. Skeldon, G.E. Thompson, Electrochim. Acta, 54 (2009) 6767-6778.

[19] A.I. Slonova, O.P. Terleeva, Protect. Met., 44 (2008) 65-75.

[20] A.L. Yerokhin, X. Nie, A. Leyland, A. Matthews, S.J. Dowey, Surf. Coat. Technol., 122 (1999) 73-93.

[21] K. Shimizu, G.E. Thompson, G.C. Wood, Thin Solid Films, 92 (1982) 231-241. 
Figure Captions

Fig. 1: Current change of aluminium during voltage sweep at $3.5 \mathrm{~V} \mathrm{~s}^{-1}$ in (a) $0.075 \mathrm{~mol} \mathrm{dm}^{-}$ ${ }^{3} \mathrm{Na}_{2} \mathrm{SiO}_{3}+0.05 \mathrm{KOH}$ and (b) $0.1 \mathrm{~mol} \mathrm{dm}^{-3}$ ammonium pentaborate electrolytes.

Fig. 2: SEM images of surfaces of aluminium specimens (a) before anodizing and after anodizing (b, c) in $0.075 \mathrm{~mol} \mathrm{dm}^{-3} \mathrm{Na}_{2} \mathrm{SiO}_{3}+0.05 \mathrm{KOH}$ electrolyte to $362 \mathrm{~V}$ and (d, e) in $0.1 \mathrm{~mol} \mathrm{dm}^{-3}$ ammonium pentaborate electrolyte to $366 \mathrm{~V}$ at a voltage sweep rate of $3.5 \mathrm{~V}$ $\mathrm{s}^{-1}$.

Fig. 3: Current transients of an aluminium microelectrode during applying pulse voltages of 390 to $420 \mathrm{~V}$ in (a) $0.075 \mathrm{~mol} \mathrm{dm}^{-3} \mathrm{Na}_{2} \mathrm{SiO}_{3}+0.05 \mathrm{KOH}$ and (b) $0.1 \mathrm{~mol} \mathrm{dm}^{-3}$ ammonium pentaborate electrolytes for $30 \mathrm{~ms}$.

Fig. 4: SEM images of surfaces of aluminium microelectrode specimens after pulse anodizing at (a) $400 \mathrm{~V}$ and (b) $420 \mathrm{~V}$ in $0.1 \mathrm{~mol} \mathrm{dm}^{-3}$ ammonium pentaborate electrolyte and at (c) $390 \mathrm{~V}$ and (d) $420 \mathrm{~V}$ in (a) $0.075 \mathrm{~mol} \mathrm{dm}^{-3} \mathrm{Na}_{2} \mathrm{SiO}_{3}+0.05 \mathrm{KOH}$ electrolyte for $30 \mathrm{~ms}$.

Fig. 5: (a) SEM image of an aluminium microelectrode specimen after pulse anodizing at $420 \mathrm{~V}$ in $0.075 \mathrm{~mol} \mathrm{dm}^{-3} \mathrm{Na}_{2} \mathrm{SiO}_{3}+0.05 \mathrm{KOH}$ electrolyte for $2 \mathrm{~ms}$. (b) SEM and X-ray images of (c) $\mathrm{Al}$ and (d) $\mathrm{O}$ of the (a) region after immersion in chromic acid-phosphoric acid mixed solution.

Fig. 6: SEM images of (a,c) film surfaces and (b,d) metal surfaces of aluminium microelectrode specimens after pulse anodizing at $420 \mathrm{~V}$ in $0.075 \mathrm{~mol} \mathrm{dm}^{-3} \mathrm{Na}_{2} \mathrm{SiO}_{3}+0.05$ $\mathrm{KOH}$ electrolyte for (a,b) $10 \mathrm{~ms}$ and (c,d) $30 \mathrm{~ms}$. The metal surfaces were disclosed by immersing the respective pulse anodized specimens in chromic acid-phosphoric acid mixed solution.

Fig. 7: SEM images of (a) film and (b) metal surfaces of aluminium microelectrode specimens after pulse anodizing at $420 \mathrm{~V}$ in $0.075 \mathrm{~mol} \mathrm{dm}^{-3} \mathrm{Na}_{2} \mathrm{SiO}_{3}+0.05 \mathrm{KOH}$ electrolyte for $2 \mathrm{~ms}$. The metal surface was disclosed by immersing the pulse anodized specimen in chromic acid-phosphoric acid mixed solution.

Fig. 8: (a, e) SEM images and X-ray images of (b, f) Al, (c, g) $\mathrm{O}$ and (d, h) Si of aluminium microelectrode specimens after pulse anodizing at $420 \mathrm{~V}$ in $0.075 \mathrm{~mol} \mathrm{dm}^{-3} \mathrm{Na}_{2} \mathrm{SiO}_{3}+0.05$ $\mathrm{KOH}$ electrolyte for (a-d) $10 \mathrm{~ms}$ and (e-h) $30 \mathrm{~ms}$. 
Fig. 9: SEM images (a) film and (b) metal surfaces of the film surface formed in $0.1 \mathrm{~mol}$ $\mathrm{dm}^{-3}$ ammonium pentaborate electrolyte at $420 \mathrm{~V}$ with $2 \mathrm{~ms}$ pulse. 
Table 1 Electrolytes used in this study (293 K)

\begin{tabular}{lcc|}
\hline Composition & $\mathrm{pH}$ & Conductivity $\left(\mathrm{S} \mathrm{cm}^{-1}\right)$ \\
\hline $0.1 \mathrm{~mol} \mathrm{dm}^{-3}\left(\mathrm{NH}_{4}\right)_{2} \mathrm{~B}_{10} \mathrm{O}_{16}$ & 8.1 & 0.014 \\
$0.075 \mathrm{~mol} \mathrm{dm}^{-3} \mathrm{Na}_{2} \mathrm{SiO}_{3}-0.05 \mathrm{~mol} \mathrm{dm}^{-3} \mathrm{KOH}$ & 12.5 & 0.025 \\
\hline
\end{tabular}




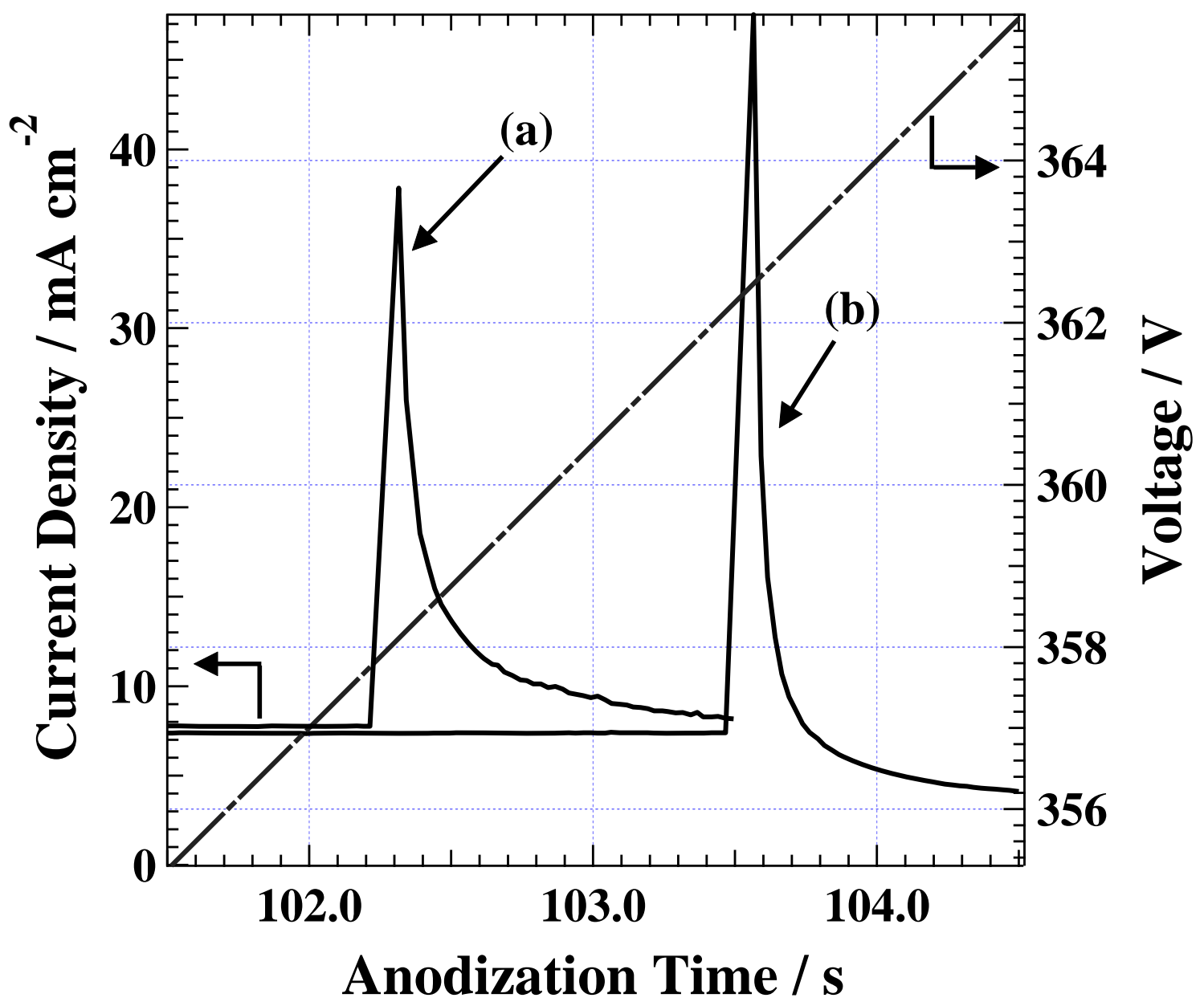

Fig. 1: Current change of aluminium during voltage sweep at $3.5 \mathrm{~V} \mathrm{~s}^{-1}$ in (a) $0.075 \mathrm{~mol} \mathrm{dm}^{-3}$ $\mathrm{Na}_{2} \mathrm{SiO}_{3}+0.05 \mathrm{KOH}$ and (b) $0.1 \mathrm{~mol} \mathrm{dm}^{-3}$ ammonium pentaborate electrolytes. 

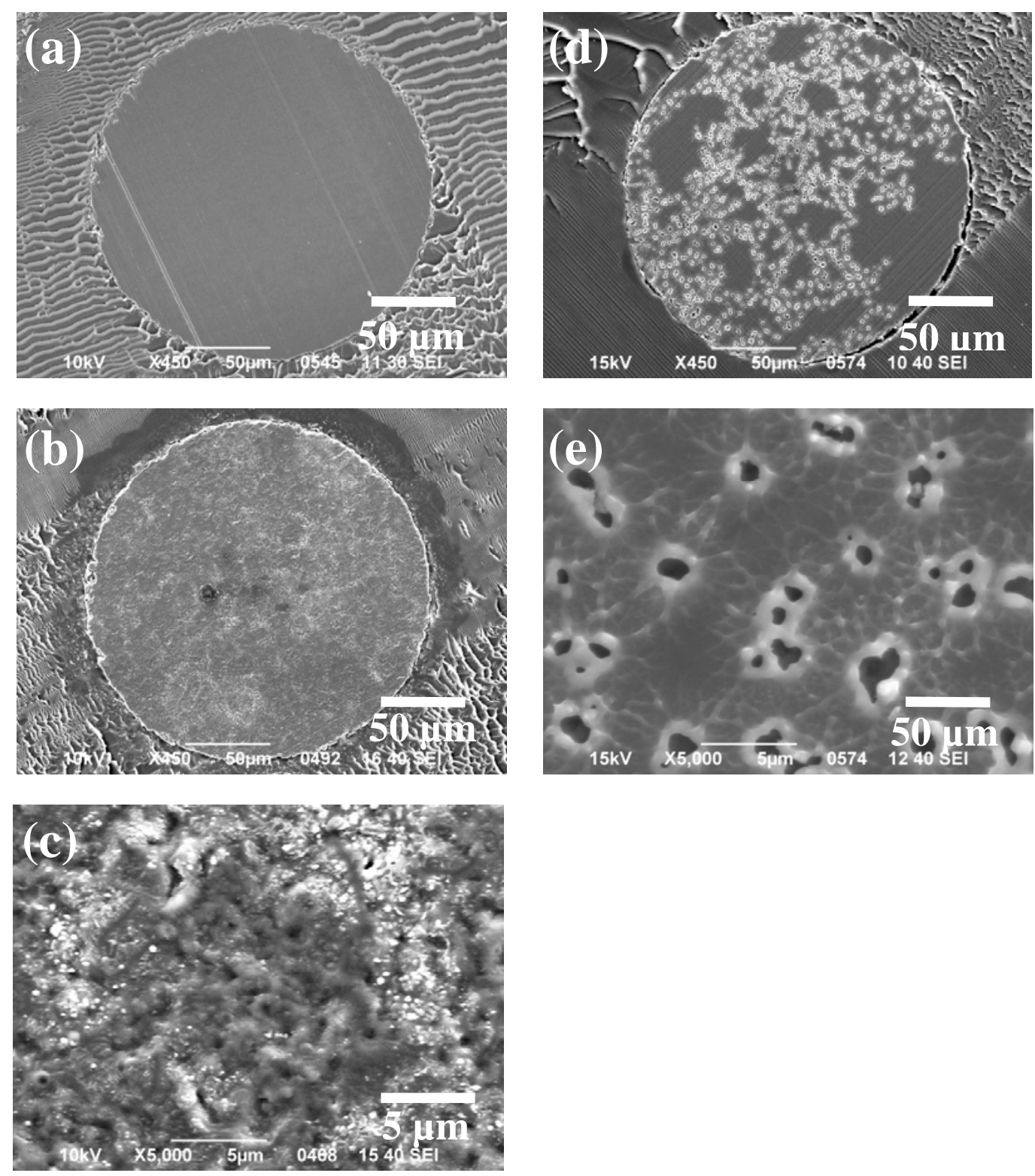

Fig. 2: SEM images of surfaces of aluminium specimens (a) before anodizing and after anodizing (b, c) in $0.075 \mathrm{~mol} \mathrm{dm}^{-3} \mathrm{Na}_{2} \mathrm{SiO}_{3}+0.05 \mathrm{KOH}$ electrolyte to $362 \mathrm{~V}$ and (d, e) in $0.1 \mathrm{~mol}$ $\mathrm{dm}^{-3}$ ammonium pentaborate electrolyte to $366 \mathrm{~V}$ at a voltage sweep rate of $3.5 \mathrm{~V} \mathrm{~s}^{-1}$. 

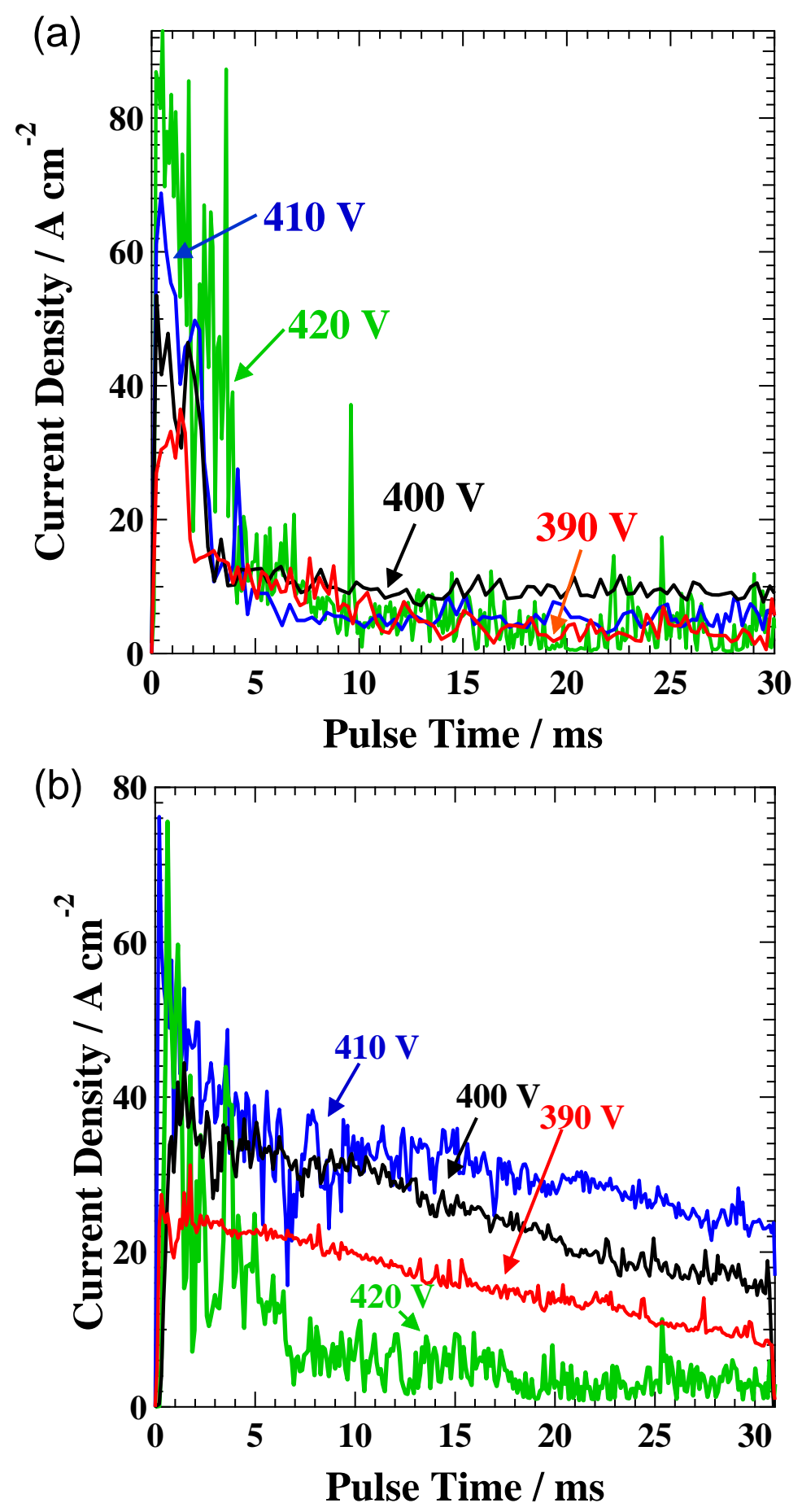

Fig. 3: Current transients of an aluminium microelectrode during applying pulse voltages of 390 to $420 \mathrm{~V}$ in (a) $0.075 \mathrm{~mol} \mathrm{dm}^{-3} \mathrm{Na}_{2} \mathrm{SiO}_{3}+0.05 \mathrm{KOH}$ and (b) $0.1 \mathrm{~mol} \mathrm{dm}^{-3}$ ammonium pentaborate electrolytes for $30 \mathrm{~ms}$. 

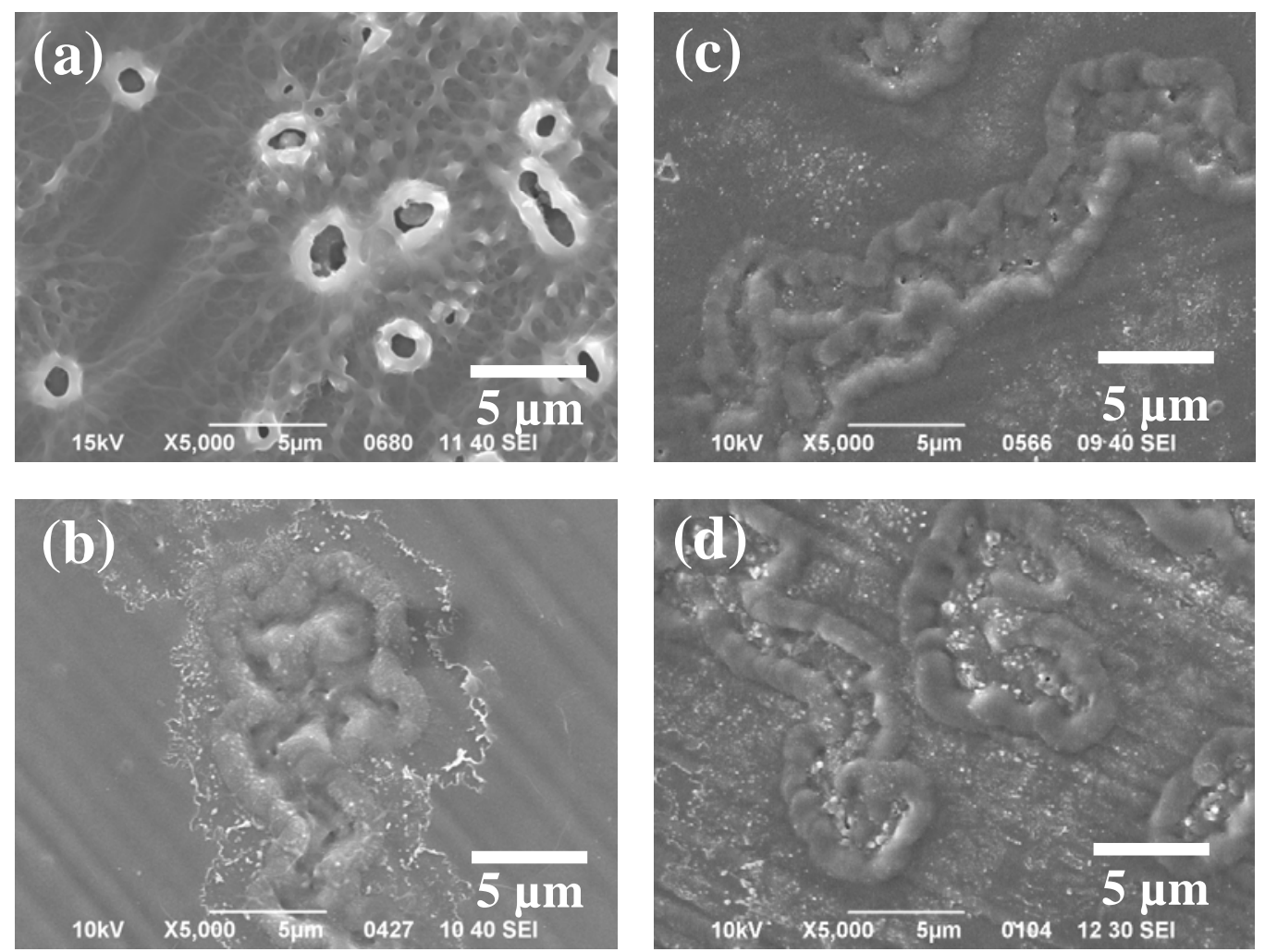

Fig. 4: SEM images of surfaces of aluminium microelectrode specimens after pulse anodizing at (a) $400 \mathrm{~V}$ and (b) $420 \mathrm{~V}$ in $0.1 \mathrm{~mol} \mathrm{dm}^{-3}$ ammonium pentaborate electrolyte and at (c) $390 \mathrm{~V}$ and (d) $420 \mathrm{~V}$ in (a) $0.075 \mathrm{~mol} \mathrm{dm}^{-3} \mathrm{Na}_{2} \mathrm{SiO}_{3}+005 \mathrm{KOH}$ electrolyte for $30 \mathrm{~ms}$. 

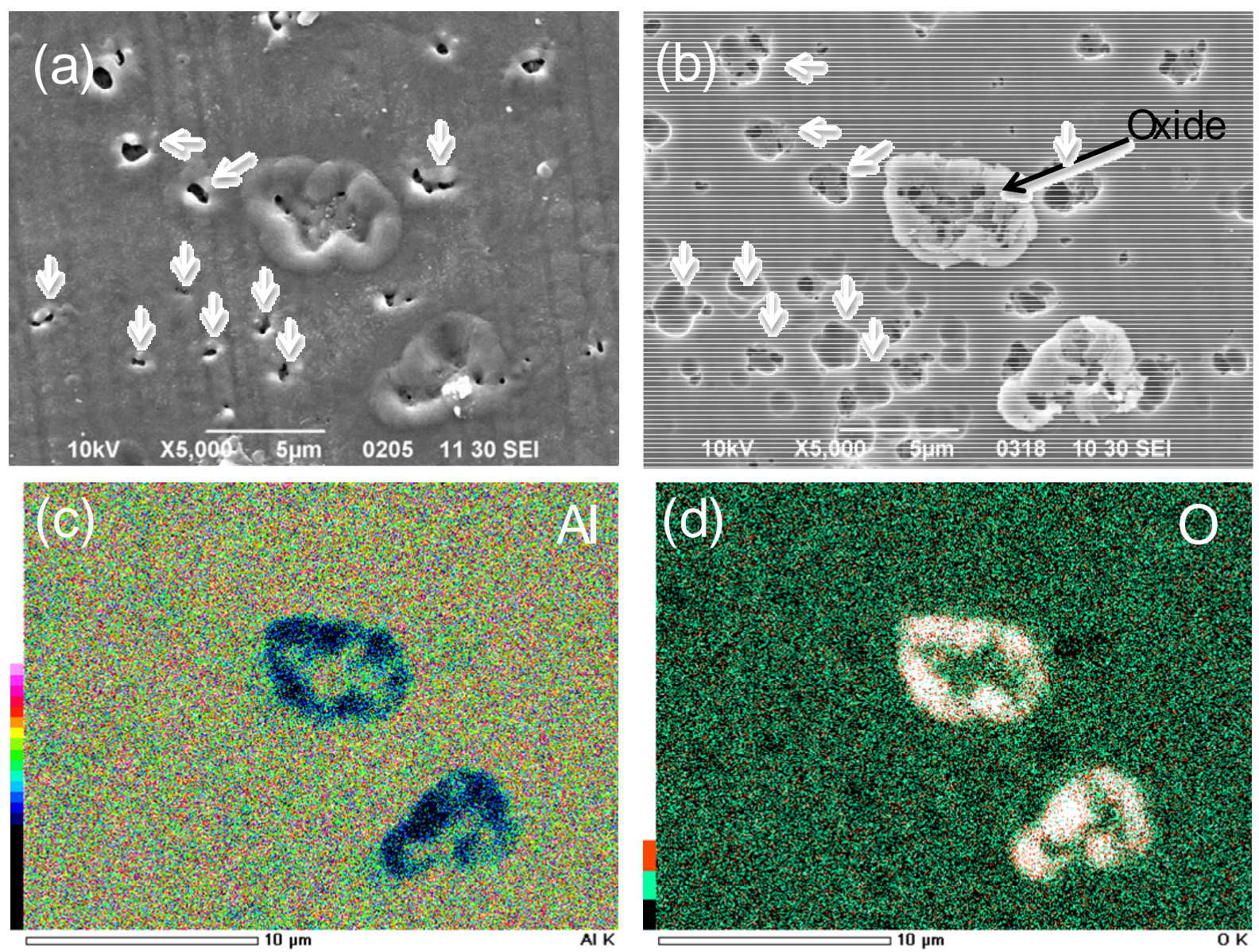

Fig. 5: (a) SEM image of an aluminium microelectrode specimen after pulse anodizing at $420 \mathrm{~V}$ in $0.075 \mathrm{~mol} \mathrm{dm}^{-3} \mathrm{Na}_{2} \mathrm{SiO}_{3}+0.05 \mathrm{KOH}$ electrolyte for $2 \mathrm{~ms}$. (b) SEM and X-ray images of (c) $\mathrm{Al}$ and (d) $\mathrm{O}$ of the (a) region after immersion in chromic acid-phosphoric acid mixed solution. 

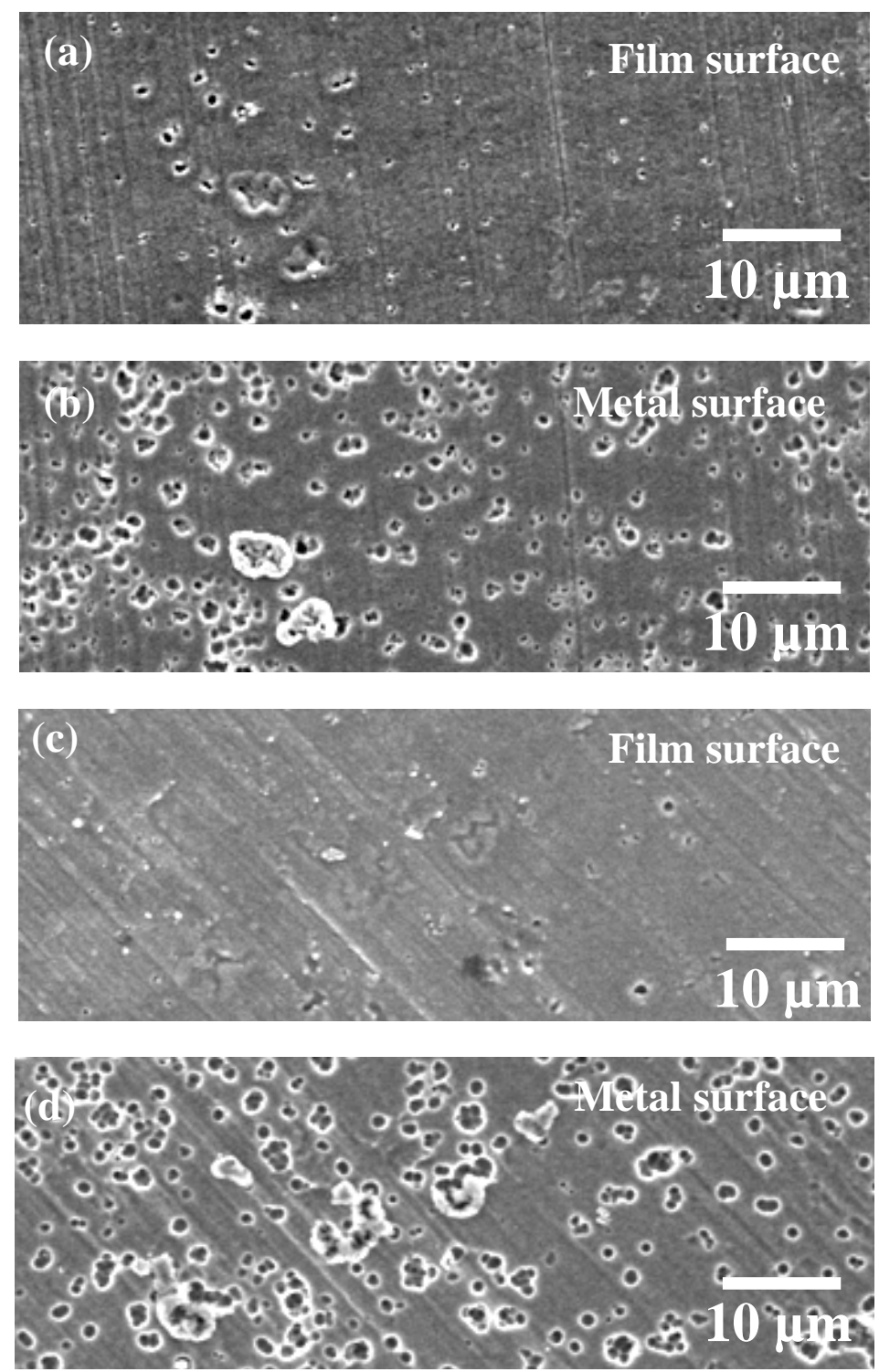

Fig. 6: SEM images of (a,c) film surfaces and (b,d) metal surfaces of aluminium microelectrode specimens after pulse anodizing at $420 \mathrm{~V}$ in $0.075 \mathrm{~mol} \mathrm{dm}^{-3} \mathrm{Na}_{2} \mathrm{SiO}_{3}+0.05 \mathrm{KOH}$ electrolyte for (a,b) $10 \mathrm{~ms}$ and (c,d) $30 \mathrm{~ms}$. The metal surfaces were disclosed by immersing the respective pulse anodized specimens in chromic acid-phosphoric acid mixed solution. 

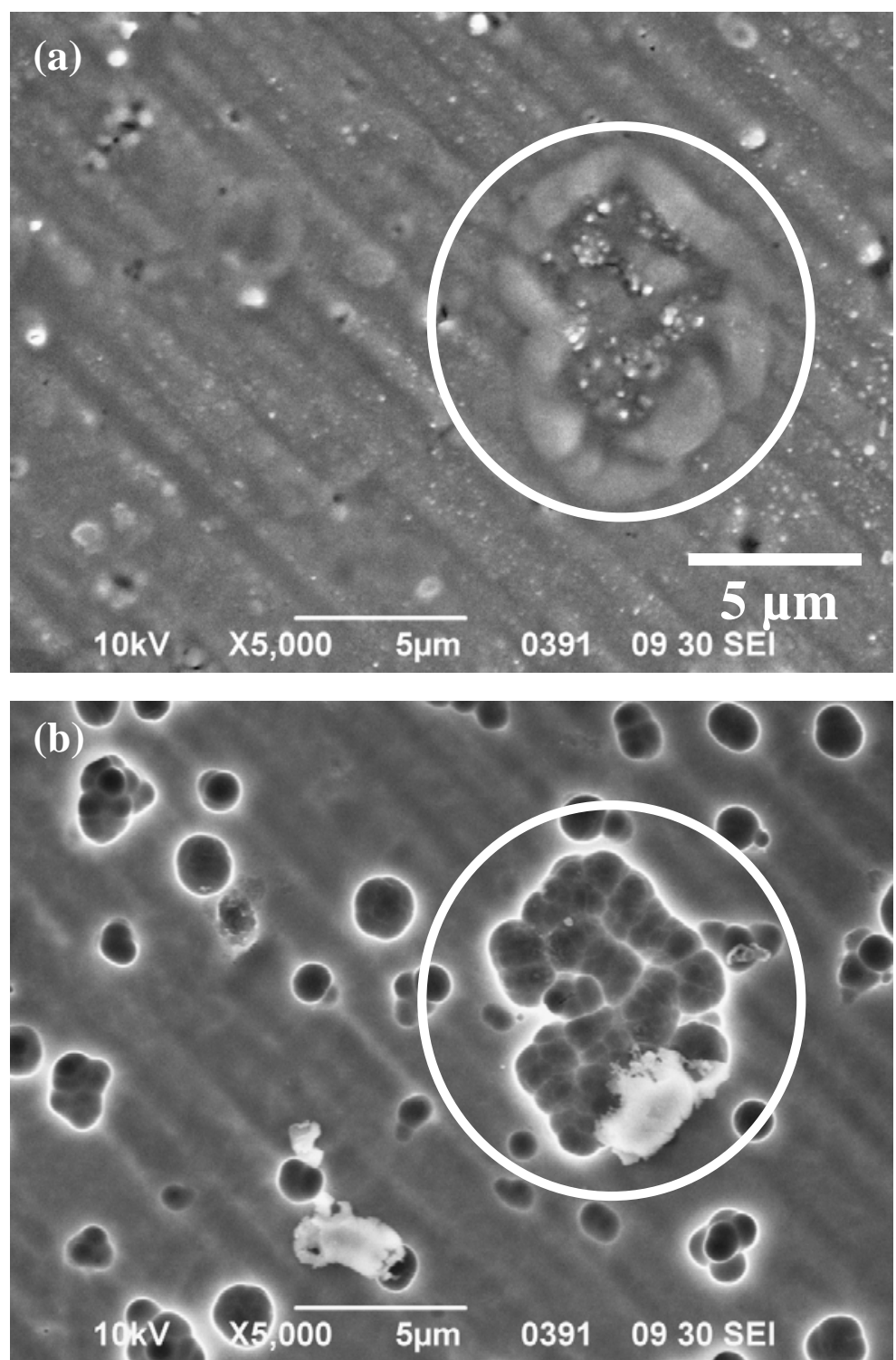

Fig. 7: SEM images of (a) film and (b) metal surfaces of aluminium microelectrode specimens after pulse anodizing at $420 \mathrm{~V}$ in $0.075 \mathrm{~mol} \mathrm{dm}^{-3} \mathrm{Na}_{2} \mathrm{SiO}_{3}+0.05 \mathrm{KOH}$ electrolyte for $2 \mathrm{~ms}$. The metal surface was disclosed by immersing the pulse anodized specimen in chromic acidphosphoric acid mixed solution. 

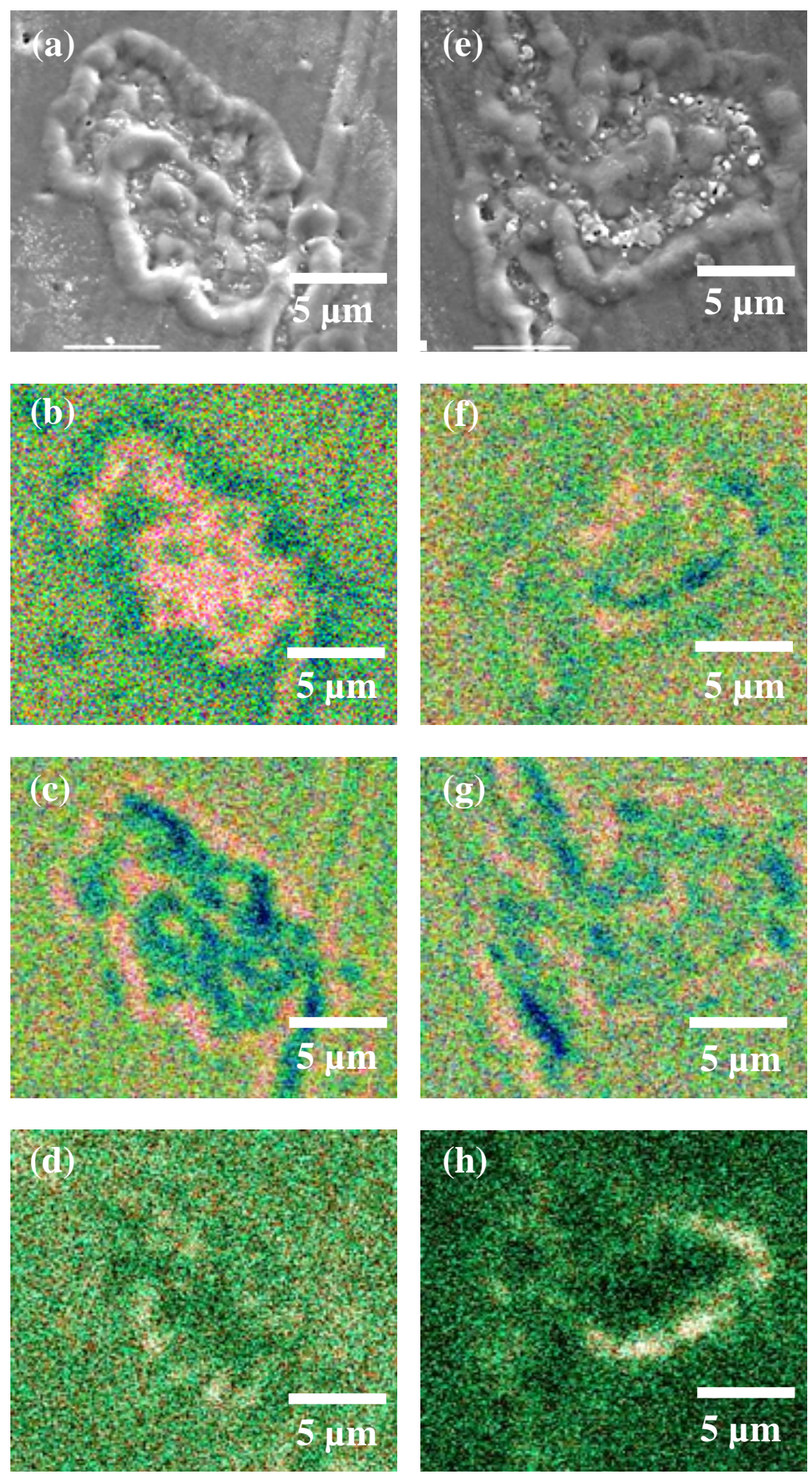

Fig. 8: (a, e) SEM images and X-ray images of (b, f) Al, (c, g) O and (d, h) Si of aluminium microelectrode specimens after pulse anodizing at $420 \mathrm{~V}$ in $0.075 \mathrm{~mol} \mathrm{dm}^{-3} \mathrm{Na}_{2} \mathrm{SiO}_{3}+0.05 \mathrm{KOH}$ electrolyte for (a-d) $10 \mathrm{~ms}$ and (e-h) $30 \mathrm{~ms}$. 

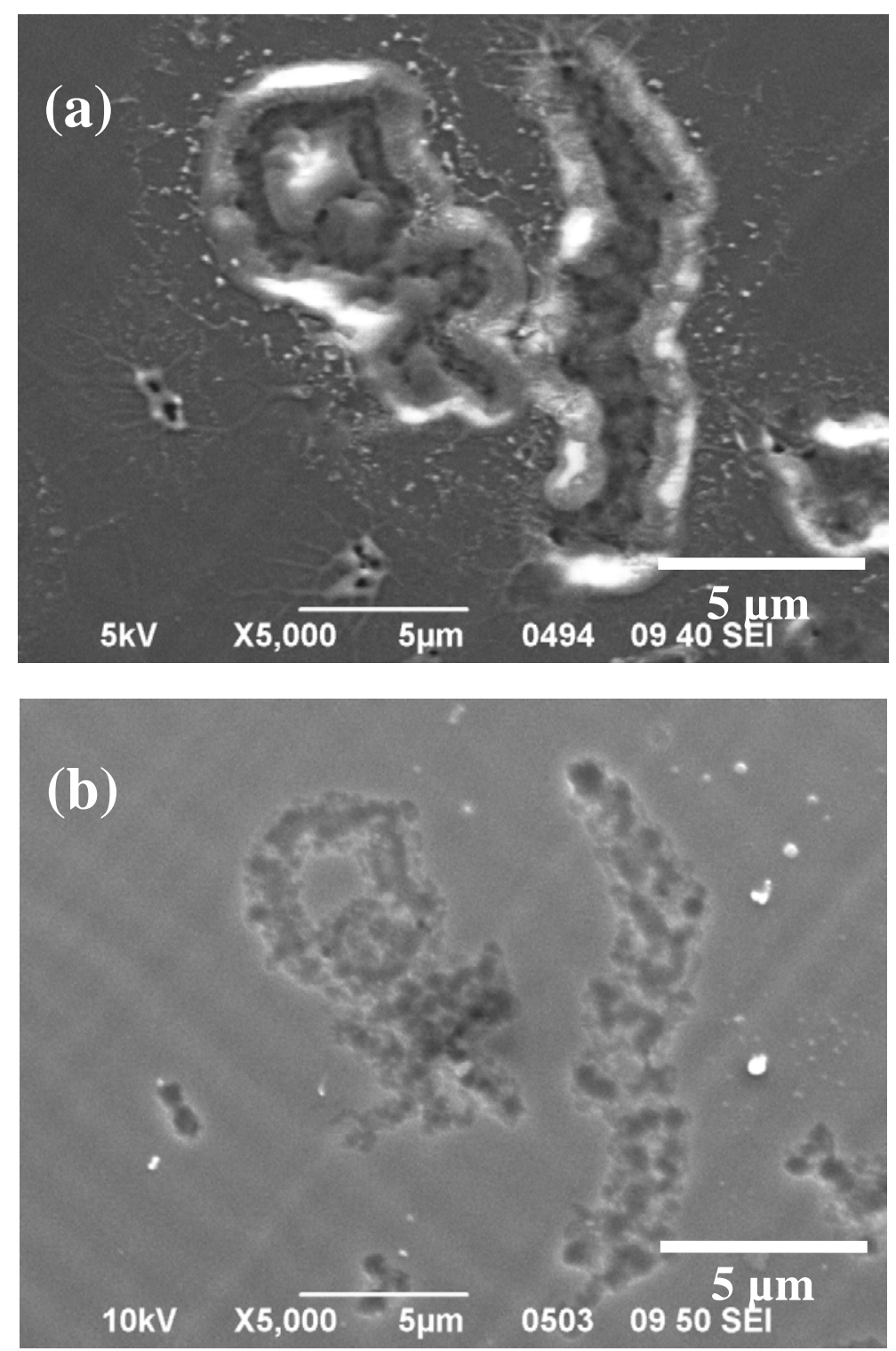

Fig. 9: SEM images (a) film and (b) metal surfaces of the film surface formed in $0.1 \mathrm{~mol} \mathrm{dm}^{-3}$ ammonium pentaborate electrolyte at $420 \mathrm{~V}$ with $2 \mathrm{~ms}$ pulse. 